\title{
Reflex Changes Induced by Clonidine in Spinal Cord Injured Patients
}

\author{
P. W. Nance, MD, FRCP(C), ${ }^{1}$ A. H. Shears, MD, $\operatorname{FRCP}(C),{ }^{1}$ D. $M$. \\ Nance, $\mathbf{P h D}^{2}$ \\ ${ }^{1}$ Division of Physical Medicine and Rehabilitation, ${ }^{2}$ Department of Anatomy, \\ Dalhousie University and the Nova Scotia Rehabilitation Centre, Halifax, Nova \\ Scotia, Canada.
}

\begin{abstract}
Summary
In a single blind study of 6 spinal cord injured (SCI) men, the effects of clonidine, a selective alpha-2 adrenergic agonist, on spasticity were compared to diazepam and placebo. Since a potential side-effect of clonidine is postural hypotension, a combination of clonidine and desipramine was also tested. Vibration of the leg will inhibit the $H$ reflex in a normal subject; whereas, this inhibition is markedly reduced in SCI patients with spasticity. A vibratory inhibition index (VII) was derived for each treatment. The pre-treatment VII was $92.08 \pm 3.15 \%$; for SCI subjects, compared to $46 \cdot 5 \pm 7 \cdot 7 \%$ for 6 normal subjects. Clonidine significantly reduced the mean index of SCI patients to $59.42 \pm 3.91 \%(p<0.001)$. The VII for placebo, diazepam and the clonidine-desipramine combination were not statistically different than the pre-treatment values in SCI patients. In conclusion, clonidine has an antispasticity effect in SCI patients, both subjectively, and objectively, in terms of vibratory inhibition of the $H$ reflex.
\end{abstract}

Key words: Spasticity; Clonidine; Alpha agonists; Spinal cord injury.

Many individuals with spinal cord injury (SCI) develop spasticity in the limbs which are innervated by spinal segments below the level of injury. The spasticity is characterised by an increase in the amplitude of reflex response as well as spontaneous movements of muscles which are no longer under voluntary control. Even in the absence of stimuli which increase spasticity, such as skin abrasions or overdistention of the bladder or bowel, spasticity may remain a serious problem to the patient. All the drugs currently used for the treatment of spasticity have major undesirable side-effects, such as muscle weakness caused by sodium dantrolene or sedation caused by diazepam (Young and Delwaide, 1981). The antispasticity effect of baclofen has been demonstrated in patients with multiple sclerosis but has not been shown to be uniformly effective in SCI patients (Roussan et al., 1985). Furthermore, none of these agents have been shown to promote neurological function. 
Histochemical studies in animals indicate that spinal cord transection results in a dramatic decrease in noradrenalin (NA) content in the spinal cord below the level of the injury and a 3-fold increase in the brain stem levels 12 to 107 days after transection (Naftchi et al., 1982). In the spinal cord, there is a dense alpha2 receptor concentration in the dorsal horns in cats, rats and humans (Unnerstall et al., 1984). Stimulation of spinal alpha-2 receptors results in the inhibition of sensory afferents (Engberg and Ryall, 1966). Inhibitory modulation of segmental spinal reflexes can be tested in human subjects by quantifying the inhibitory effect of vibration on the $\mathrm{H}$ reflex of the legs (Delwaide, 1985). Furthermore, it has been shown that vibratory inhibition of the $\mathrm{H}$ reflex is markedly reduced or eliminated in SCI patients coincident with the development of spasticity (Burke and Ashby, 1972).

Preliminary reports of clonidine as a treatment in SCI patients suggest that clonidine may improve spasticity but that the main limitation of clonidine use in SCI patients is the augmentation of postural hypotension (Tuckman et al., 1982; Nance et al., 1985; Maynard, 1986). Since the combination of clonidine and desipramine, a NA reuptake blocker, will result in reversal of the antihypertensive effect of clonidine (Briant et al., 1973) we also examined the effect of this combination in our subjects. Therefore, the purpose of this study was to use inhibition of the $\mathrm{H}$ reflex by vibration, the Achilles deep tendon reflex and the duration of clonus as measures of spasticity in SCI patients before and after treatment with (1) clonidine (2) clonidine plus desipramine (3) diazepam and (4) placebo.

\section{Methods}

Six spinal cord injured men with spasticity consented to participate in the study. The mean age was $25 \cdot 4$ years and the mean duration of SCI was $4 \cdot 6$ years. In addition, 6 normal age-matched subjects consented to the measurements of their VII, described as follows. The $\mathrm{H}$ reflex was recorded via an active electrode on the skin at the mid-point between the popliteal crease and medial malleolus, the approximate location of the soleus muscle and an indifferent electrode was placed $8 \mathrm{~cm}$ distal to the active electrode, over the Achilles tendon. The tibial nerve was stimulated by a $3 \mathrm{~cm}$ bar electrode on the skin in the popliteal fossa with the cathode proximal to the anode. The intensity of the stimulus was adjusted to achieve the maximum amplitude of the $\mathrm{H}$ reflex. The maximum amplitude of 5 trials was measured. A Wahl hand held vibrator, frequency of vibration $=60 \mathrm{~Hz}$, was then applied to the Achilles tendon at the heel for 20 seconds, the same intensity of stimulus was then delivered to evoke the $\mathrm{H}$ reflex during continual tendon vibration and the maximum of 5 trials was compared to the non-vibrated reflex. A vibratory inhibition index (VII) was then derived using the formula $\mathrm{H}$ reflex amplitude (vibrated)/ $\mathrm{H}$ reflex amplitude (control) $\times 100^{\circ}{ }_{0}$.

The Achilles deep tendon reflex was evoked by a percussion hammer blow to the tendon. The subject was positioned such that the knee was bent to 90 degrees and the ankle was in neutral position. The response was measured by a plastic footplate equipped with a strain gauge and the recording was made via a Grass Model 7 polygraph. This measurement recorded the latency and am- 


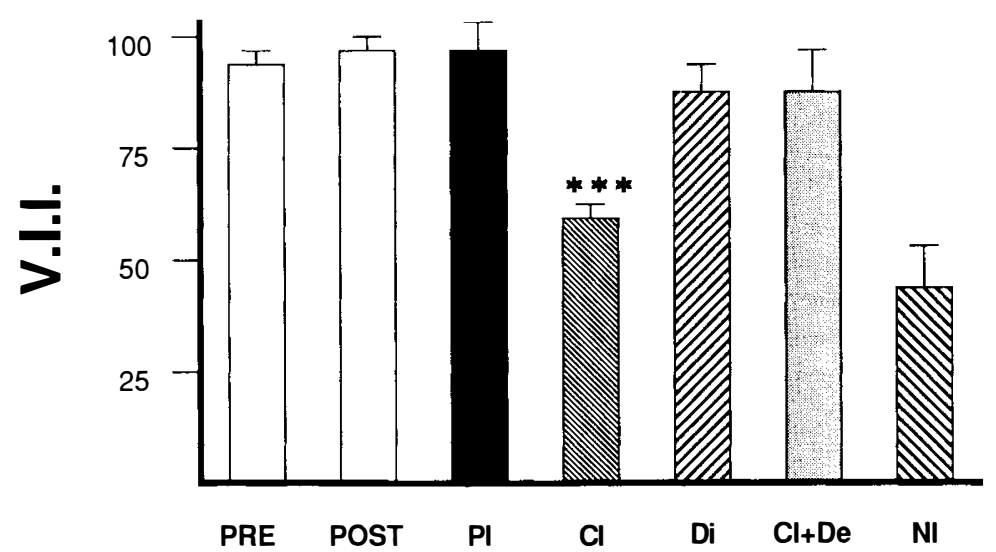

Figure Vibratory Inhibition Index (VII) in 6 SCI patients and 6 normal (Nl) subjects, pre- and post-treatment, $\mathrm{Pl}=$ placebo, $\mathrm{Cl}=$ clonidine, $\mathrm{Di}=$ diazepam and $\mathrm{Cl}+\mathrm{De}=$ clonidine + desiparamine. $\left({ }^{\star \star \star} \mathrm{p}<0.001\right)$

plitude of the reflex in arbitrary units and the duration of reflex activity (clonus) in seconds. The electrodiagnostic equipment used was a TECA TE4 electromyograph, and PA4A6 preamplifier.

Each experimental condition lasted 1 week, which included a 7 day pre- and post- (no drug) treatment and data was recorded on experimental days 3 and 5. The experimental conditions were as follows: 1 week clonidine, one $0.05 \mathrm{mg}$ dose on the first day and increased by 1 dose per day to a maximum of 4 per day, then decreased 1 dose per day; likewise, diazepam ( $5 \mathrm{mg}$ dose), desipramine (25 $\mathrm{mg}$ dose) and placebo were increased and decreased in 1 dose per day increments over a 1 week period. The medications were crushed and placed in similar appearing capsules. The patients were not aware of the sequence of treatments; however, the observing physician was aware of the treatment sequence for each patient. The sequence of active drug administration was counterbalanced across subjects. Statistical significance was determined by an analysis of variance with repeated measures and all experimental conditions compared to control values by Duncan's multiple range test (post hoc).

\section{Results}

Vibratory inhibition of the $H$ reflex

As illustrated in the Figure, the VII was significantly reduced from a pretreatment mean index ( \pm standard error of the mean) of $92.08 \pm 3.15 \%$ to $59.43 \pm 3.91 \%$ by clonidine $(\mathrm{p}<0.001)$. The diazepam treatment mean index $(82.08 \pm 9.77 \%)$ was not significantly different from the pre-treatment values. Similarly, the combination of desipramine plus clonidine was comparable to the pre-treatment measurement $(81 \cdot 81 \pm 5 \cdot 23 \%)$. Placebo, pre- and post-treatment scores were comparable. The VII derived from 6 normal subjects was $46.5 \pm$ $7.7 \%$. 


\section{Achilles deep tendon reflex and clonus}

The measurement of these parameters was made on 5 subjects and was unaltered by the various treatment conditions (Table).

\section{Summary of clinical observations}

Although this was a single study in that each subject was not informed of the particular sequence of drugs which was received, all 6 subjects correctly identified each drug treatment by their subjective impression of the drugs' effects. All subjects stated that their spontaneous spasms were less frequent and lessened in 'severity' while taking clonidine. Two subjects felt fatigue during clonidine and diazepam treatments. However, these same subjects slept through the testing procedure during the course of the diazepam treatment, but not during the clonidine treatment. One subject who normally spoke very infrequently became talkative during his treatment with clonidine. The syndrome of autonomic dysreflexia, characterised by sweating and vasodilation above the level of the spinal cord lesion, headache, bradycardia and hypertension was observed in 3 subjects prior to entering this study. Typically this syndrome was associated with bladder dystension or reflex voiding. In these subjects, clonidine treatment subjectively lessened the sweating, flushing and headache. Upon withdrawal of clonidine, one subject noted 'rebound' sweating and increased spasms. One subject noted dryness of the mouth during clonidine treatment which was increased with the addition of desipramine.

One subject complained of nausea and altered visual acuity during clonidine treatment. No patient complained of dizziness; however, 3 patients who had a postural drop of $20 \mathrm{mmHg}$ of systolic blood pressure prior to the study were noted to have had a $40 \mathrm{~mm}$ decrease of systolic blood pressure while sitting upright during clonidine treatment. This decrement in the systolic blood pressure was not symptomatic and the subjects denied dizziness or light-headedness. With the addition of desipramine, the postural drop of blood pressure was observed to be $20 \mathrm{~mm}$, which was comparable to the pre-treatment condition of the subjects. One subject described feeling irritable during clonidine treatment, with the addition of desipramine, this irritability was increased and was accompanied by feelings of paranoia.

\section{Discussion}

Vibration of a limb has been shown previously to suppress or abolish tendon jerks and the $\mathrm{H}$ reflex in normal human subjects (De Gail et al., 1966). Furthermore, the $\mathrm{H}$ reflex is not significantly reduced by vibration in humans with spasticity due to stroke, multiple sclerosis and SCI (Burke and Ashby, 1972; Taylor et al., 1984; Verrier et al., 1975). The present data indicates an abnormally high VII score for the SCI patients relative to normal controls which is consistent with previously published data for others. The present results indicate that clonidine reduces spasticity and concurrently restores vibratory inhibition of the $\mathrm{H}$ reflex in our SCI subjects to levels which are comparable to normals.

Since it is well known that norepinephrine concentration is markedly diminished in the spinal cord distal to injury, one interpretation of this data is that 
Table Effects of drugs on deep tendon reflex (DTR) in SCI subjects

\begin{tabular}{|c|c|c|c|c|c|c|c|c|c|c|c|c|}
\hline \multirow[b]{2}{*}{ Subjects } & \multicolumn{2}{|c|}{$\begin{array}{c}\text { Pre- } \\
\text { experiment }\end{array}$} & \multicolumn{2}{|c|}{$\begin{array}{c}\text { Post- } \\
\text { experiment }\end{array}$} & \multicolumn{2}{|c|}{ Placebo } & \multicolumn{2}{|c|}{ Clonidine } & \multicolumn{2}{|c|}{$\begin{array}{l}\text { Clonidine + } \\
\text { desipramine }\end{array}$} & \multicolumn{2}{|c|}{ Diazepam } \\
\hline & DTR * & Clonus $\star \star$ & DTR & Clonus & DTR & Clonus & DTR & Clonus & DTR & Clonus & DTR & Clonus \\
\hline 1 & $3 \cdot 5$ & 0.0 & $3 \cdot 5$ & $0 \cdot 0$ & $4 \cdot 5$ & 0.0 & $5 \cdot 0$ & 2.5 & $5 \cdot 0$ & $5 \cdot 0$ & $5 \cdot 0$ & $5 \cdot 0$ \\
\hline 2 & $4 \cdot 2$ & $64 \cdot 0$ & $2 \cdot 5$ & $63 \cdot 0$ & $4 \cdot 5$ & $162 \cdot 5$ & $1 \cdot 0$ & $50 \cdot 0$ & $4 \cdot 5$ & $12 \cdot 0$ & $1 \cdot 8$ & $180 \cdot 0$ \\
\hline 3 & $2 \cdot 0$ & $17 \cdot 5$ & 1.5 & $31 \cdot 0$ & 1.5 & $20 \cdot 0$ & $1 \cdot 5$ & $36 \cdot 0$ & $12 \cdot 5$ & $90 \cdot 0$ & $8 \cdot 3$ & $18 \cdot 0$ \\
\hline 4 & $5 \cdot 0$ & $120 \cdot 0$ & $4 \cdot 5$ & $130 \cdot 0$ & $4 \cdot 5$ & $120 \cdot 0$ & 1.5 & $60 \cdot 0$ & $6 \cdot 5$ & $45 \cdot 0$ & $5 \cdot 5$ & $130 \cdot 0$ \\
\hline 5 & $5 \cdot 5$ & $5 \cdot 0$ & $4 \cdot 5$ & $5 \cdot 0$ & $4 \cdot 5$ & $5 \cdot 0$ & $7 \cdot 0$ & $0 \cdot 0$ & $5 \cdot 5$ & 0.0 & $5 \cdot 5$ & $0 \cdot 0$ \\
\hline Mean & $4 \cdot 0$ & $41 \cdot 2$ & $3 \cdot 3$ & $45 \cdot 8$ & 3.9 & $61 \cdot 4$ & $3 \cdot 2$ & $29 \cdot 6$ & $6 \cdot 8$ & $30 \cdot 4$ & 5.21 & $66 \cdot 6$ \\
\hline \pm SEM & 0.61 & $22 \cdot 7$ & 0.58 & $23 \cdot 8$ & $0 \cdot 6$ & $33 \cdot 3$ & $1 \cdot 1$ & $12 \cdot 2$ & 1.46 & $16 \cdot 8$ & 1.04 & $37 \cdot 0$ \\
\hline
\end{tabular}

$\star$ Values represent the relative amplitude in arbitrary units

$\star \star$ Values represent duration of clonus in seconds

clonidine treatment is stimulating alpha-2 receptors in the spinal cord and thereby restoring the noradrenergic inhibition which has been lost following SCI. Paradoxically, the amplitude of the deep tendon reflexes and the duration of clonus evoked by mechanical stimulation was not significantly altered during clonidine treatment. In spinal injured rats, clonidine will also stimulate alpha-1 receptors located on ventral horn motor cells thereby increasing the amplitude of the flexor reflex (Kehne et al., 1985). This non-selective excitation of both alpha- 1 and alpha- 2 receptors in the spinal cord below the level of the lesion may account for the discrepancy between the clonidine induced restoration of vibratory inhibition and lack of reduction in the amplitude of the deep tendon reflex or a decrease in the duration of clonus. Our results indicate that desipramine is effective in reversing the hypotensive effect of clonidine but the antispasticity effect of clonidine is also reversed. One possible explanation is that some descending NA remains in our subjects such that the block of NA reuptake by desipramine at the spinal level counteracts the inhibition produced by clonidine. Another explanation may be that modification of reflex inhibition in a spastic subject is occurring at a supraspinal site where both clonidine and desipramine could be acting and that stimulation at that site modified spinal reflexes below the level of the SCI.

Diazepam treatment has been reported to restore vibratory inhibition of the $\mathrm{H}$ reflex in spastic subjects (Delwaide, 1985) but others have reported no effect (Verrier et al., 1975). Similarly, in the present study no effect of diazepam on the $\mathrm{H}$ or deep tendon reflexes was observed, although the low dose and oral route of administration may have been a factor. In summary, clonidine has an antispasticity effect in SCI patients that is recognised subjectively and demonstrable physiologically by restoration of vibratory inhibition of the $\mathrm{H}$ reflex. However, a similar effect of diazepam could not be demonstrated.

\section{Acknowledgements}

P.W.N. is a recipient of a Lalia B. Chase Fellowship awarded through the Dalhousie Medical Research Foundation.

Supported in part by the Medical Research Council of Canada. 


\section{References}

BRIANT RH, REID JL, DOLLERY CT 1973 Interaction between clonidine and desipramine in man. British Medical fournal 1:522-523.

BURKe D, AshBY P 1972 Are spinal 'presynaptic' inhibitory mechanisms suppressed in spasticity? Fournal of the Neurological Sciences 15:321-26.

De Gail P, LANCE JW, Neilson PD 1966 Differential effects on tonic and phasic reflex mechanisms produced by vibration of muscles in man. Fournal of Neurology, Neurosurgery and Psychiatry 29:1-11.

DELWAIDE PJ 1985 Electrophysiological analysis of the mode of action of muscle relaxants in spasticity. Annals of Neurology 17:90-95.

ENGBERG I, RYALL RW 1966 The inhibitory action of noradrenaline and other monoamines on spinal neurons. Fournal of Physiology 185:298-322.

Gillies JD, LANCE JW, NEILSON PD, et al., 1969 Presynaptic inhibition of the monosynaptic reflex by vibration. Fournal of Physiology 205:329-339.

KEHNE JH, Gallagher DW, DAvis M 1985 Spinalization unmasks clonidine's alpha-1-adrenergic medicated excitation of the flexor reflex in rats. Fournal of Neuroscience 5:1583-1590.

MAYNARD FM 1986Early clinical experience with clonidine in spinal spasticity. Paraplegia 24:175-182.

NAFTChi NE, Kirschner AK, Demeny M, et al., 1982 Spinal Cord Injury, Spectrum, New York, pp 67-80.

Nance PW, Shears AH, Nance DM 1985 Clonidine in spinal cord injury. Canadian Medical Association fournal 133:41-42.

Roussan M, Terrence C, Fromm G 1985 Baclofen versus diazepam for the treatment of spasticity and long-term follow-up of baclofen therapy. Pharmatherapeutica 4:278-284.

TAYLOR S, ASHBY P, VERRIER M 1984 Neurophysiological changes following traumatic spinal lesions in man. Fournal of Neurology, Neurosurgery and Psychiatry 47:1102-1108.

Tuckman J, Chu DS, Petrillo CR, et al., 1982 Spinal Cord Injury, Spectrum, New York, pp 133-136.

UNNERSTALL JR, KopAJTIC TA, KUHAR MJ 1984 Distribution of alpha-2 agonist binding sites in the rat and human central nervous system: Analysis of some functional, anatomic correlates of the pharmacologic effects of clonidine and related adrenergic agents. Brain Research Reviews 7:69-101.

Verrier M, MacLeod S, Ashby P 1975 The effect of diazepam on presynaptic inhibition in patients with complete and incomplete spinal cord lesions. Canadian fournal of Neurological Sciences 2: 179-184.

Young RR, Delwaide PJ 1981 Drug Therapy: Spasticity, Parts I, II. New England fournal of Medicine 304:28-33, 96-99. 